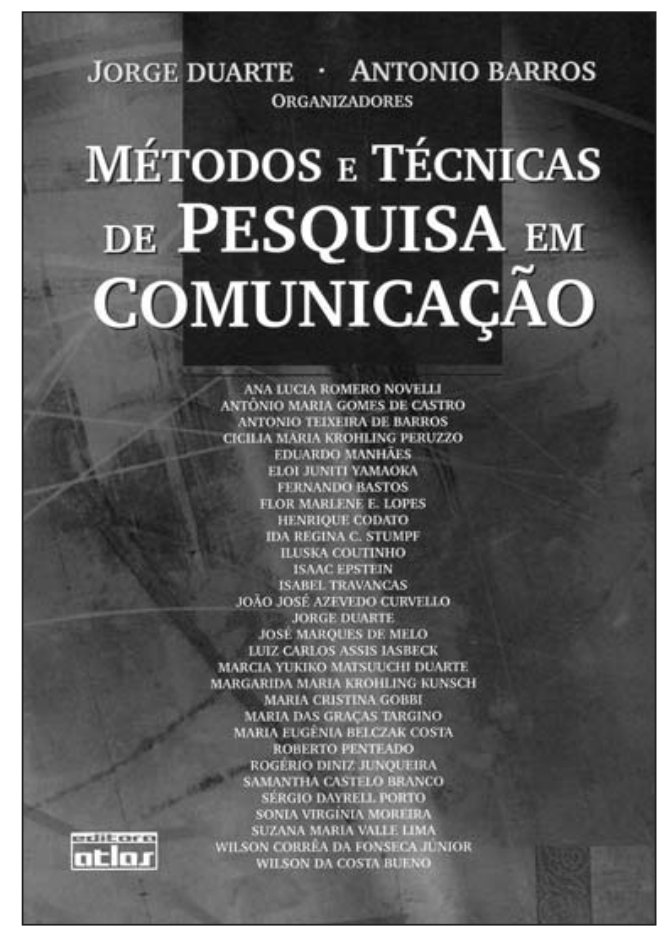

Jorge Duarte e Antonio Barros (Orgs.)

Métodos e técnicas de pesquisa em Comunicação - $2^{a}$ ed.

São Paulo:

Atlas, 2006.

384 páginas

Leandro Leonardo Batista

- Mestre e Doutor em Ciências da Comunicação pela University of North Carolina - Chapel Hill - USA

- Professor-doutor do Departamento de Relações Públicas, Propaganda e Turismo da ECA-USP

- leleba@usp.br 


\section{Métodos de pesquisa: uma visão geral}

$\mathrm{O}$ s estudos em Comunicação com objetivo de testar teorias ou avaliar efeitos de esforços comunicativos procuram o entendimento sobre produção, processos e efeitos de símbolos e sinais (visuais e/ ou verbais), dentro de contextos que podem ser interpessoais, intrapessoais, organizacionais, populacionais, políticos, instrucionais e tantos outros. A combinação de diferentes modos de comunicar com uma grande diversidade de contextos, tendo a comunicação como aspecto central, deixa clara a necessidade de uma vasta gama de métodos de pesquisa e técnicas investigativas procurando entender não apenas os efeitos persuasivos da comunicação, mas também considerações sobre as formas como indivíduos usam os meios e os conteúdos de esforços de comunicação e como estes meios e conteúdos definem ou ajudam a definir as relações sociais.

Este ponto é central na consideração do livro organizado por Jorge Duarte e Antonio Barros. Tomando como base qualquer uma das várias características de seu conteúdo, pode-se afirmar que este é um livro único na literatura acadêmica de Comunicações. Inicialmente, chama a atenção a enorme quantidade de autores (30) reunidos em torno de um único tema: a pesquisa em Comunicações. Estes autores trazem uma abrangência de técnicas e métodos, advindos de diversas áreas do conhecimento que se mostram muito próprias para o estudo de Comunicações, uma ciência em desenvolvimento e que, por esta razão, toma "emprestado" conhecimento de outros domínios que já vêm sendo estudados há mais tempo, como Antropologia, Direito, Engenharia, Filosofia, Psicologia, Sociologia, entre outros, cujos pensamentos e focos estão representados por autores destas áreas.

Neste livro, alia-se esta base mais tradicional de pesquisa com pesquisadores mais diretamente ligados aos contornos das áreas definidas como componentes da Ciência da Comunicação, tais como Jornalismo, Relações Públicas, Semiótica e Ciência da Informação, formando uma estrutura de métodos de estudo e técnicas em pesquisa que cobre praticamente toda a necessidade de projetos dentro desta nova ciência, sejam eles para análise da percepção de determinado problema de uma organização entre seus diversos públicos em relação aos seus objetivos e esforços de comunicação, ou efeitos em promoção de eventos, testes de mensagens, ou ainda, simplesmente, avaliar (quantificar e qualificar) exposição na mídia.

Além do background dos autores, deve-se destacar que os temas selecionados pelos organizadores são oportunos, uma vez que definem desde onde se insere a pesquisa cien- 
tífica, seus limites, funções e poderes, até definições específicas de como se desenvolve um trabalho científico, passando pela discussão do papel de vários métodos e a "oferta" de diversas técnicas, tanto qualitativas como quantitativas. Nota-se, ainda, o cuidado dos organizadores em apresentar técnicas de pesquisa com diferentes níveis de intrusão e interatividade com seus objetos de pesquisa, mas sem a preocupação de separá-las em métodos quantitativos e qualitativos, o formato mais comum em livros deste tipo. Assim, temos capítulos sobre técnicas pouco intrusivas, como pesquisa bibliográfica, semiótica, estudo de caso, análise de conteúdo, análise de discurso e análise de imagens, que permitem uma observação do objeto a ser pesquisado sem, no entanto, causar modificação neste, facilitando novas análises e novas interpretações e servindo, desta maneira, para um escrutínio maior e mais profundo do mesmo objeto sob diversos pontos de vista.

Estão incluídas, também, as técnicas mais intrusivas que, apesar de afetarem seus objetos de estudo enquanto se os observa, têm a qualidade de poder penetrar mais profundamente nas observações, trazendo à tona, principalmente, os efeitos causados pelos diversos modos pelos quais a comunicação atua sobre os seus targets. Neste ponto, fica mais clara a diferenciação entre os métodos qualitativos, com o objetivo de gerar focos de observação, e os métodos quantitativos, que se preocupam em quantificar estes efeitos e, quando possível, inferir para populações não-observadas diretamente. Dentro disto, o livro oferece técnicas de entrevistas em profundidade, estudos etnográficos, pesquisa de opinião e grupo focal.

Cabe ressaltar, ainda, que alguns métodos de observação incluídos no livro podem utilizar apenas uma ou combinar várias das diversas técnicas apresentadas, com o propósito de permitir um entendimento específico de esforços comunicacionais, tomando sempre como base o aspecto científico dentro da Ciência da Comunicação. Assim, são discutidos o método biográfico, que pode fazer uso, por exemplo, das técnicas de análise de conteúdo e pesquisa em profundidade; a metodologia folkcomunicacional, que é facilitada por técnicas como semiótica, análise de discurso, grupo focal e pesquisa de opinião; o método de análise documental, fundamentado em análise de conteúdo, de impressos, documentos sonoros ou de imagem; ou ainda o método de estudo de caso, focado, geralmente, em episódios recentes e necessitando de várias das técnicas já mencionadas acima, desde as menos intrusivas, como a análise documental, até as totalmente intrusivas, como a etnográfica.

Alguns métodos descritos no livro têm objetivos didáticos sobre a sua utilização, em vez de serem um manual aplicativo. Este é o caso, por exemplo, do capítulo que discute o uso da Internet, descrevendo desde a sua concepção e desenvolvimento até problemas causados pela característica principal do meio de gerar resultados de pesquisa acima da capacidade do usuário em avaliar cada item gerado. Dentro desta concepção didática, no capítulo são discutidos os métodos de operadores booleanos e outros re- 
cursos que limitam os resultados como forma de melhorar o foco da pesquisa. Devese ressaltar o valor das instruções descritas também pela sua longevidade, pois serão sempre úteis para orientar pesquisadores na utilização do método.

No entanto, recentes desenvolvimentos nesta ferramenta de pesquisa mereceriam menção, como é o caso dos bancos de dados de trabalhos científicos mantidos pelas editoras internacionais, como o Blakwell Synergy, Proquest, Ingenta, Emerald e outros, além da principal fonte nacional, que é o sítio portal de pesquisa mantido pela Coordenação de Aperfeiçoamento de Pessoal de Nível Superior (Capes) - (www.periodicos.capes.gov.br) e que agrega um grande número de publicações nacionais e internacionais de altíssimo valor para pesquisadores acadêmicos.

O valor destas fontes é corroborado pelos recentes desenvolvimentos na área de acesso a periódicos criados pela empresa Google, que são o Google Acadêmico (textos em português e espanhol) e o Google Scholar (textos em inglês) que, embora disponibilizados após a publicação do livro, são de fundamental importância na pesquisa científica. Estas duas ferramentas permitem identificar trabalhos publicados por meio de palavras-chave, bem como onde estes trabalhos foram citados em publicações posteriores, permitindo uma "varredura" das linhas em que o tema pesquisado está inserido. Estas informações complementam tanto o capítulo sobre pesquisa bibliográfica como o que apresenta o uso da Internet como método de pesquisa.

Em uma obra que cobre um espectro tão amplo de métodos e técnicas, não se pode esperar uma profunda abordagem individual de cada tema. Ao contrário, a qualidade que pode ser destacada no conteúdo da obra é a interação entre métodos e técnicas. O conjunto da obra permite definir métodos e escolher as técnicas mais apropriadas, considerando o propósito da pesquisa e do pesquisador. Pesquisadores interessados em aprofundamento em técnicas específicas podem fazer uso da bibliografia citada nos capítulos e dos métodos de pesquisa bibliográfica e/ou de uso da Internet como base para identificar outras fontes. 